\title{
Modified Arai and Mikami Melanin Formation Test of Streptomycetes
}

\author{
YUZURU MIKAMI, KOJI YOKOYAMA, AND TADASHI ARAI \\ Department of Antibiotics, Research Institute for Chemobiodynamics, Chiba University, Chiba, Japan
}

Improvements are presented and procedural details are clarified concerning the melanin formation test of streptomycetes of Arai and Mikami (1972).

Melanin formation tests for Streptomyces identification have been subjected to considerable study $(4,5)$ and their usefulness has been confirmed. In 1972 Arai and Mikami proposed a simplified test (1). The purpose of this note is to present improvements and clarify procedural details of that test.

First, the substrate, L-3,4-dihydroxyphenylalanine (L-DOPA) or L-tyrosine, should not be incorporated into the growth medium. The culture filtrate is tested for tyrosinase activity only after growth has occurred. The procedure that is the most simple, rapid, and sensitive is to add 15 to $20 \mathrm{mg}$ of L-DOPA or DL-DOPA directly to $10 \mathrm{ml}$ of culture filtrate. L-DOPA is preferred to L-tyrosine because L-DOPA is readily soluble in water and L-tyrosine is not. If $\mathrm{L}$ tyrosine is chosen as the substrate, use $0.04 \%$ in place of the $0.4 \%$ concentration of L-tyrosine as given in the original description. A pink to red coloration within 5 to 10 min after the addition of L-DOPA is a positive test.

Secondly, several precautions are necessary to obtain definitive results. (i) L-DOPA readily oxidizes in solution, but the autooxidation is usually slow and the color that results is dark brown instead of pink to red. (ii) Maximum production of tyrosinase occurs between 9 to 15 days and 6 to 12 days of incubation when the culture filtrates of Streptomyces griseus ISP 5236 and Streptomyces phaeochromogenes ISP 5073 are used, respectively (Table 1 ). The former strain is a low and the latter is a high producer of tyrosinase. We recommend, therefore, that tests be conducted after 1 week of incubation and, if negative at 1 week, again after 9 to 12 days of incubation when stationary cultures are used. (iii) When the culture filtrate is dark colored with nonmelanoid pigment as is encountered with Streptomyces lavenduligriseus ISP 5478, Streptomyces viridochromogenes ISP 5110, and Streptomyces atrofaciens ISP 5475, the filtrate is diluted 1:5 or 1:10 with buffer (1) before the addition of L-DOPA. The diluted filtrates of these strains give positive reactions. (iv) If a culture has a pink cast before the test is conducted, a deepening of color after the addition of L-DOPA is a positive reaction.
TABLE 1. Time courses of tyrosinase production of Streptomyces griseus ISP 5236 and Streptomyces phaeochromogenes ISP $5073^{a}$

\begin{tabular}{ccc}
\hline \multirow{2}{*}{$\begin{array}{c}\text { Incubation time } \\
\text { (days) }\end{array}$} & \multicolumn{2}{c}{ OD at $480 \mathrm{~nm}$} \\
\cline { 2 - 3 } & S.griseus & S.phaeochromogenes \\
\hline 0 & 0 & 0 \\
1 & 0 & 0.130 \\
3 & 0 & 0.530 \\
6 & 0.110 & 0.990 \\
9 & 0.140 & 1.240 \\
12 & 0.150 & 1.335 \\
15 & 0.147 & 0.284 \\
18 & 0.140 & 0.110 \\
\hline
\end{tabular}

a The assay system contained $2 \mathrm{ml}$ of the culture filtrate, $2 \mathrm{ml}$ of phosphate buffer (pH 5.9), and $1 \mathrm{ml}$ of DL-DOPA solution. The reaction mixture was incubated at $37^{\circ} \mathrm{C}$ for $5 \mathrm{~min}$ (S. phaeochromogenes) and $10 \mathrm{~min}$ ( $S$. griseus) and measured spectrophotometrically.

${ }^{b} \mathrm{OD}$, optical density.

When the modified procedure is used, the correlation between dark coloration of peptoneyeast extract-iron agair and positive melanin formation from L-DOPA is about 96 to $99 \%$. Only a few strains, such as $S$. griseus ISP 5236 , were peptone-yeast extract-iron agar negative and melanin positive $(2,3)$.

\section{REPRINT REQUESTS}

Address reprint requests to: Dr. Tadashi Arai, Department of Antibiotics, Research Institute for Chemobiodynamics, Chiba University, Chiba, Japan.

\section{LITERATURE CITED}

1. Arai, T., and Y. Mikami. 1972. Chromogenicity of Streptomyces. Appl. Microbiol. 23:402-406.

2. Arai, T., and Y. Mikami. 1972. Chromogenesis mirabilis in Streptomyces griseus. Appl. Microbiol. 24:768771.

3. Mikami, Y., K. Takahashi, and T. Arai. 1971. Taxonomic studies of Streptomyces griseus ISP 5236 and Streptomyces ornatus ISPS 5307. Ann. Rep. Inst. Food Microbiol. Chiba Univ. 24:47-56.

4. Shirling, E. B., and D. Gottlieb. 1966. Methods for characterization of Streptomyces species. Int. J. Syst. Bacteriol. 16:313-340.

5. Shirling, E. B., and D. Gottlieb. 1976. Retrospective evaluation of International Streptomyces Project taxonomic criteria, p. 9-41. In T. Arai (ed.), Actinomycetes, the boundary microorganisms. Toppan Co. Ltd., Tokyo. 